\title{
Optimization of Ultrasound-Assisted Extraction of Flavonoids from Cryptotaenia japonica Hassk. and Evaluation of Antioxidant Activity
}

\author{
Jun $\mathrm{Lu}^{1,2}$, Youzhi $\mathrm{Xu}^{1,2}$, Mengxin Yang ${ }^{1}$, Xinjing $\mathrm{Fu}^{1}$, Feijun Luo ${ }^{1,2}$ \& Zhonghai $\mathrm{Li}^{1,2}$ \\ ${ }^{1}$ College of Food Science and Engineering, Central South University of Forestry and Technology, Changsha, \\ Hunan, P. R. China \\ ${ }^{2}$ National Engineering Laboratory of Rice and By-Product Deep Processing, Central South University of \\ Forestry and Technology, Changsha, Hunan, P. R. China \\ Correspondence: Zhonghai Li, No. 498 Shaoshan North Road, Changsha 410004, P. R. China. Tel: \\ 86-731-8562-3072. Fax: 86-731-8562-3071. E-mail: csuftlzh@sina.com
}

Received: March 13, 2015 Accepted: April 26, 2015 Online Published: June 15, 2015

doi:10.5539/jas.v7n7p138 URL: http://dx.doi.org/10.5539/jas.v7n7p138

\begin{abstract}
The present study optimized the ultrasound assisted extraction (UAE) conditions using Box-Behnken design (BBD) with response surface methodology (RSM) and evaluated the antioxidant activity of total flavonoids from Cryptotaenia japonica Hassk. The results showed that the optimum conditions were 55\% ethanol concentration, $1: 30 \mathrm{~g} / \mathrm{mL}$ solid to solvent ratio, $400 \mathrm{~W}$ ultrasound power, $70 \mathrm{~min}$ extraction time and 3 cycles. Under these optimum conditions, the extraction yield of total flavonoids was $33.110 \pm 0.742 \mathrm{mg} / \mathrm{g}$ DW (dry weight), which was well consisted with value predicted by the model. The RSM optimized extract was subsequently checked for antioxidant activity by 2,2-diphenyl-1-picrylhydrazyl (DPPH) radical scavenging assay, hydroxyl scavenging assay and reducing power assay. Under the flavonoid concentration of $3.0 \mathrm{mg} / \mathrm{mL}$, antioxidant scavenging activity were of $79.87 \pm 2.7 \%$ and $71.60 \pm 2.6 \%$ for DPPH and hydroxyl assay while for reducing power and absorbance of $1.200 \pm 0.053$ was obtained. Furthermore, the composition in antioxidants were investigated, and the luteolin and apigenin were determined. The results indicated that ultrasound assisted extraction is a promising technique for extraction of flavonoids from C. japonica Hassk and the flavonoids could be explored as a potential antioxidant agent for use in medicine or functional foods.
\end{abstract}

Keywords: flavonoids, Cryptotaenia japonica Hassk., ultrasound-assisted extraction, optimization, response surface methodology, antioxidant activity

\section{Introduction}

Studies of active components from natural sources such as fruits and vegetables, especially flavonoids compounds, have greatly increased in recent years. Flavonoids include a large number of compounds which have been proven to possess a broad spectrum of biochemical and pharmacological activities such as antioxidant (Floreset, Wu, Negrin, \& Kennelly, 2015; Zielinski et al., 2014), antibacterial (Cushnie \& Lamb, 2011), antiviral (S. Y. Kang, J. Y. Kang, \& Oh, 2012), etc. Therefore, highly efficient methods of extracting and isolating total flavonoids for supplements or medicinal use attract world-wide interest and studies (Cherng, Chiag, \& Chiang, 2008; Pourcel, Routaboul, Cheynier, Lepiniec, \& Debeaujon, 2007; Joana Gil-Chávez et al., 2013). Cryptotaenia japonica Hassk. (Yaojiaoban, in Chinese) is a popular forestry vegetable due to its flavor and Chinese folk medicine use its medical effect for skin itch and traumatic injury (Yang, Xia, Li, \& Cheng, 2010). Some studies have reported on the compositions and antioxidant activity of $C$. japonica (Cheng, Lin, Yen, \& Yu, 2010; Cheng Lin, Yu, \& Peng, 2008; Okude \& Hayashi, 1970; Yao, Sang, \& Zhou, 2010; Yao \& Ren, 2011), but few studies refer to the extraction of flavonoids ( $\mathrm{Li}$, Zhu, \& Deng, 2006). Ultrasound-assisted extraction is the new technology that has become widely applied in the extraction of a variety of bioactive ingredient (Kiani, Sun, Zhang, Al-Rubeai, \& Naciri, 2013; Şahin \& Şaml1, 2013; Wang et al., 2013). It has the notable advantages for decreasing the consumption of solvent and extraction time, increasing yield and ease of use (Bimakr et al., 2011; Grigonis, Venskutonis, Sivik, Sandahl, \& Eskilsson, 2005) comparing with other extraction techniques such as heating, boiling, refluxing and soxhlet extraction. However, there is no report about using ultrasonic technique to extract total flavonoids from C. japonica and evaluate the antioxidant potential. In this study, we use the ultrasound assisted extraction to separate total flavonoids from C. japonica by RSM and to evaluate the 
antioxidant activity by hydroxyl radical, DPPH radicals and reducing power assays. Finally, the main flavonoid compositions in extract were analyzed by reverse phase high-performance liquid chromatography (RP-HPLC).

\section{Materials and Methods}

\subsection{Materials and Reagents}

Cryptotaenia japonica was harvested in May from west region of Hunan Province, China. The plant was authenticated by Prof. Zhonghai Li and voucher specimen (YY.201105) deposited at the College of Food Science and Engineering, Central South University of Forestry and Technology, Changsha, Hunan, China. All plant materials were washed and separated into root and aerial parts. The latter were dried in an oven for $24 \mathrm{~h}$ at $60{ }^{\circ} \mathrm{C}$ and powdered to a 60 mesh by a disintegrator, and stored in sealed polyethylene bag in a dry and dark place until use. Rutin was purchased from National Institutes for Food and Drug Control (analytical grade), DPPH were purchased from Sigma Chemicals Co., Ltd, sodium nitrite, sodium carbonate, aluminum nitrite, sodium hydroxide and ethanol were purchased from Sinopharm Chemical Reagent Co., Ltd. All other chemicals and solvents were of analytical grade.

\subsection{Sonication Treatment}

Ultrasound-assisted extraction experiments were carried out with an ultrasonic cell disruption machine which was equipped with a cylindrical titanium alloy probe $(12.70 \mathrm{~mm}$ diameter). (JY92-Ш, Ningbo Shizhi Biotechnology Co., Ltd, China). A powdered sample of $3.0 \mathrm{~g}$ was placed into a $200 \mathrm{~mL}$ of glass flask, soaked with different ratio of ethanol solvent (varing ethanol concentration from $50 \%$ to $70 \%$; varing liquid to solid ratio from 1:30 to 1:50), then sonicated for 40-60 min at a constant working frequency of $60 \mathrm{kHz}$ and pulse $7 \mathrm{~s}$ on and $5 \mathrm{~s}$ off with different times at the designed ultrasound power. The extract solution was filtered by a Busher funnel and the filtrate was centrifuged for $10 \mathrm{~min}$ at $6000 \mathrm{rpm}$. The supernatant was collected to detect the concentration of total flavonoids. The combined extracts solution under the optimized condition were evaporated under vacuum and were lyophilized with a freeze dryer system (Ningbo Shizhi Biotechnology Co., Ltd, China) at $-55^{\circ} \mathrm{C}$. The crude flavonoid was later redissolved in ethanol to obtain the designed concentration for the evaluating antioxidant activity.

\subsection{Determination of Total Flavonoids Content}

Total flavonoids were measured spectrophotometrically using a modified colorimetric method (Zhu, Wang, Liu, Xia, \& Tang, 2010) with slight modification. Briefly, $1 \mathrm{~mL}$ of the sample solution was accurately removed and placed in a volumetric flask $(10 \mathrm{~mL})$ where $0.6 \mathrm{~mL}$ of NaNO2 $(5 \%)$ solution was added. The solution was shaken and stood for 6 minutes at room temperature. Additionally $0.5 \mathrm{ml}$ of $10 \%(\mathrm{~W} / \mathrm{V}) \mathrm{Al}\left(\mathrm{NO}_{3}\right)_{3}$ was added and allowed to stand for an additional 6 minutes prior to the addition of $3.0 \mathrm{~mL}$ of $4.3 \% \mathrm{NaOH}$, followed by addition of $70 \%$ ethanol $(\mathrm{v} / \mathrm{v})$ to the scale, shaken, and left to stand for $15 \mathrm{~min}$ before detection. The absorbance was measured at $507 \mathrm{~nm}$ using an ultraviolet-visible spectrophotometer (Shanghai precision instrument Co., Ltd, Shanghai, China), using the sample solution without coloration as blank solution. Rutin was used as a reference for the standard curve, the regression equation was $\mathrm{A}=1.0286 \mathrm{C}-0.0161(\mathrm{R} 2=0.9993)$. All data were reported as mean $\pm \mathrm{SD}$ for three replicate measurements. When calculating extraction yield of flavonoids, the following formula was used:

$$
\mathrm{X}=(\mathrm{C} \times \mathrm{V} \times \mathrm{D}) / \mathrm{M}
$$

Where, $X(\mathrm{mg} / \mathrm{g})=$ extraction yield of flavonoids; $\mathrm{C}(\mathrm{mg} / \mathrm{mL})=$ flavonoids content of test solution calculated by standard curve; $\mathrm{V}(\mathrm{mL})=$ volume of test solution; $\mathrm{D}=$ total dilution value; $\mathrm{M}(\mathrm{g})=$ mass of test sample.

\subsection{Evaluation of Antioxidant Activity}

The free radical scavenging activity was measured by DPPH test according to the method described by Zhang, $\mathrm{He}$, and $\mathrm{Hu}(2011)$ with some modifications. The $0.4 \mathrm{mmol} / \mathrm{L}$ solution of DPPH in $95 \%$ ethanol was prepared daily before UV measurements. Two milliliter of the tested sample was thoroughly mixed with $2.0 \mathrm{~mL}$ of freshly prepared DPPH solution. The mixture was shaken vigorously and left to stand in the dark for $30 \mathrm{~min}$, and the absorbance was then measured at $517 \mathrm{~nm}$ against a blank. The antioxidant capacity of samples was also estimated in another assay according to the procedure described by Guo et al. (2011). The reagents were added into a reaction tube in the following order: $0.3 \mathrm{~mL}$ of $20 \mathrm{mM}$ sodium salicylate, $1.0 \mathrm{~mL}$ of $1.5 \mathrm{mM} \mathrm{FeSO}, 1.0$ $\mathrm{mL}$ of various concentrations of sample solution, $0.7 \mathrm{~mL}$ of $6 \mathrm{mM} \mathrm{H}_{2} \mathrm{O}_{2}$. The solution was mixed immediately, and placed in a $37^{\circ} \mathrm{C}$ water bath for $1 \mathrm{~h}$. The absorbance measurement of the mixture was recorded at $510 \mathrm{~nm}$ against a blank. The reducing power was measured according to the method described by Guo et al. (2011) with slight modifications. An aliquot of each sample $(1.0 \mathrm{~mL})$, of different concentrations, was mixed with $2.5 \mathrm{~mL}$ of phosphate buffer $(200 \mathrm{mM}, \mathrm{pH} 6.6)$ followed by $2.5 \mathrm{~mL}$ of $1 \%$ potassium ferricyanide $\left[\mathrm{K}_{3} \mathrm{Fe}(\mathrm{CN})_{6}\right]$. The mixture 
was incubated for $20 \mathrm{~min}$ in a water bath at $50{ }^{\circ} \mathrm{C}$. After the incubation, $1.0 \mathrm{~mL}$ of $10 \%$ trichloroacetic acid (TCA) was added, followed by centrifugation at $3000 \mathrm{r} / \mathrm{min}$ for $10 \mathrm{~min}$. The supernatant $(2.5 \mathrm{~mL})$ was mixed with 2.5 $\mathrm{mL}$ of distilled water and $0.5 \mathrm{~mL}$ of $0.1 \%$ ferric chloride $\left(\mathrm{FeCl}_{3}\right)$; then the absorbance was measured at $700 \mathrm{~nm}$ against a blank in the spectrophotometer.

\subsection{HPLC Analysis}

The analysis of total flavonoids was carried out by a Shimadzu LC-20A HPLC system (Shimadzu, Japan) via a reversed-phase $\mathrm{C} 18$ column $(150 \mathrm{~mm} 4.6 \mathrm{~mm}$, I.D., $3 \mu \mathrm{m})(\mathrm{CNW})$, maintained at $25^{\circ} \mathrm{C}$. The mobile phase was methanol water $(58: 42, \mathrm{v} / \mathrm{v})$ with a $\mathrm{pH}$ of 3 adjusted with phosphoric acid $(\mathrm{pH}=4.2)$. All standards and sample were dissolved in methanol and filtrated through a $0.25 \mu \mathrm{m}$ membrane filter prior to use. The flow rate was set at $0.7 \mathrm{~mL} / \mathrm{min}$ throughout the runs. The injection volume was $10 \mu \mathrm{L}$ for each run and the PDA detector was set to a wavelength of $270 \mathrm{~nm}$. The calibration curve, based on six kinds of flavonoid standard solutions, showed excellent linearity over the range of $0.221-122 \mu \mathrm{g} / \mathrm{mL}$. The retention times of luteolin and apigenin were 7.79 min and $11.56 \mathrm{~min}$, respectively. The chromatographic peaks of the analytes were identified by comparing their retention times and UV spectra with those of the reference standards. Quantity calculations were made according to the linear calibration curves of standards.

\subsection{Box-Behnken Design}

A three-variable, three-level Box-Behnken design (BBD) with 15 experimental runs was used in this optimization study based on the results of preliminary experiments. The ethanol concentration (X1), ultrasonic time (X2), extraction times (X3) were independent variables selected to be optimized for the extraction of Cryptotaenia japonica Hassk flavonoids. Each variable set at the three levels. Extraction yield (Y) was taken as the response of the designed experiments. The coded and uncoded (actual) levels of the independent variables are given in Table 1. A second-order polynomial regression model was used to express the yield as a function of the independent variables as follows:

$$
Y=a_{0}+\sum_{i=1}^{3} a_{i} X_{i}+\sum_{i=1}^{3} a_{i i} X_{i}^{2}+\sum_{i \neq j=1}^{3} a_{i j} X_{i} X_{j}
$$

Where, Y represents the response variables, $\alpha_{0}$ is a constant, $\alpha_{i}, a_{i i}$ and $a_{i j}$ are the linear, quadratic and interactive coefficients, respectively. $\mathrm{X}_{\mathrm{i}}$ and $\mathrm{X}_{\mathrm{j}}$ are the levels of the independent variables.

Table 1. Box-Behnken design of the levels of factors

\begin{tabular}{lllll}
\hline Independent variables & Coded symbols & -1 & 0 & 1 \\
\hline Ethanol concentration (\%) & $\mathrm{X} 1$ & 50 & 60 & 70 \\
Ultrasonic time(min) & $\mathrm{X} 2$ & 50 & 60 & 70 \\
Extraction times & $\mathrm{X} 3$ & 1 & 2 & 3 \\
\hline
\end{tabular}

\subsection{Statistical Analysis}

The Design expert (Version 8.0.5b, Stat-Ease Inc., USA) were used to design BBD experiment as well as for regression and graphical analysis of the experimental results. All analyses were performed in triplicate and all experimental results were expressed as mean \pm SD. Analysis of variance was performed by an ANOVA procedure. $P$ values $<0.05$ were regarded as significant and $P$ values $<0.01$ as very significant.

\section{Results and Discussion}

\subsection{BBD and Response Surface Analysis}

Results of Box-Behnken design (BBD) analysis were shown in Table 2. The observed responses of the fifteen experiments were presented in Table 2. Multiple regression analysis was used to analyze the data and the second-order polynomial equation was derived from regression analysis as follows:

$$
\begin{aligned}
& Y=-97.87717+2.99776 \mathrm{X} 1+0.57261 \mathrm{X} 2+12.95783 \mathrm{X} 3-2.83 \mathrm{E}-3 \mathrm{X} 1 \mathrm{X} 2-1.0307 \mathrm{X} 1 \mathrm{X} 3 \\
& +0.064275 \mathrm{X} 2 \mathrm{X} 3-0.022583 \mathrm{X} 1^{2}-2.94833 \mathrm{E}-3 \mathrm{X} 2^{2}-1.74408 \mathrm{X} 3^{2}
\end{aligned}
$$

Table 3 showed the ANOVA results of response surface for extraction yield. As shown in Table 3, the model F-value of "Prob $>$ F" $<0.0001$ demonstrated that the model is highly significant at the $1 \%$ level, and the F-value for lack of fit $(P=0.138)$ also indicated that the model was a good fit. The value of determinations coefficient $\left(\mathrm{R}^{2}\right)$ was 0.9927 , indicating a good agreement between experimental and predicted values which can explain 
99.27\% variability of the responses. The value of adjusted determinant coefficient $\left(\operatorname{adj}-\mathrm{R}^{2}=0.9797\right)$ suggested that the total variation of $97.97 \%$ for total flavonoids is attributed to the independent variables and only about $2.03 \%$ of the total variation cannot be explained by the model. The lower value of CV $(1.9142 \%)$ indicated that the experimental was highly reliable. The model was very adequate for the prediction with the range of variable employed.

Table 2. Experimental design and results of Box-Behnken design

\begin{tabular}{lllll}
\hline Run & $\begin{array}{l}\text { Ethanol concentration } \\
(\%) \mathrm{X} 1\end{array}$ & $\begin{array}{l}\text { Ultrasonic time } \\
(\mathrm{min}) \mathrm{X} 2\end{array}$ & $\begin{array}{l}\text { Extraction times } \\
\mathrm{X} 3\end{array}$ & $\begin{array}{l}\text { Extraction yield } \\
(\mathrm{mg} / \mathrm{g})\end{array}$ \\
\hline 1 & -1 & 0 & -1 & $21.020 \pm 0.139$ \\
2 & 1 & 0 & -1 & $19.507 \pm 0.276$ \\
3 & 1 & 0 & 1 & $26.517 \pm 1.232$ \\
4 & -1 & 1 & 0 & $28.533 \pm 1.180$ \\
5 & 1 & 1 & 0 & $25.611 \pm 1.518$ \\
6 & -1 & -1 & 0 & $24.770 \pm 0.867$ \\
7 & 1 & -1 & 0 & $22.343 \pm 1.274$ \\
8 & 0 & 1 & 1 & $33.312 \pm 0.500$ \\
9 & 0 & 0 & 0 & $28.413 \pm 0.363$ \\
10 & 0 & -1 & 1 & $26.612 \pm 1.764$ \\
11 & 0 & -1 & -1 & $21.261 \pm 0.903$ \\
12 & 0 & 1 & -1 & $23.977 \pm 0.553$ \\
13 & 0 & 0 & 0 & $27.620 \pm 1.207$ \\
14 & -1 & 0 & 1 & $30.110 \pm 2.243$ \\
15 & 0 & 0 & 0 & $27.707 \pm 1.445$ \\
\hline
\end{tabular}

Table 3 also showed that the quadratic coefficients of ethanol concentration (X1) $(P=0.0042)$, ultrasonic time (X2) $(P=0.0002)$, extraction times $(X 3)(P<0.0001)$, and the interaction between ultrasonic time and extraction times $(\mathrm{X} 1 \mathrm{X} 3)(P=0.0093)$ for flavonoids extract yield are significant at the level of $P<0.05$ or $P<0.01$, while the cross product coefficients of X1X2 and X2X3 were non-significant at the 0.05 level. These results indicated that the changes in ultrasonication time and extraction times had a significant effect on the flavonoid extraction yield.

Table 3. ANOVA of response for UAE experiments

\begin{tabular}{clllll}
\hline Source & Sum of Squares & DF & Mean Square & F Value & $P$-value $($ Prob $>$ F) \\
\hline Model & 172.4425 & 9 & 19.1603 & 75.9727 & $<0.0001$ \\
X1 & 6.2216 & 1 & 6.2216 & 24.6695 & 0.0042 \\
X2 & 25.2228 & 1 & 25.2228 & 100.0111 & 0.0002 \\
X3 & 106.7845 & 1 & 106.7845 & 423.4128 & $<0.0001$ \\
X1X2 & 0.3204 & 1 & 0.3204 & 1.2702 & 0.3109 \\
X1X3 & 4.2498 & 1 & 4.2498 & 16.8509 & 0.0093 \\
X2X3 & 1.6525 & 1 & 1.6525 & 6.5524 & 0.0507 \\
X1 & 18.831 & 1 & 18.831 & 74.6672 & 0.0003 \\
X2 ${ }^{2}$ & 0.321 & 1 & 0.321 & 1.2726 & 0.3105 \\
X3 & 11.2314 & 1 & 11.2314 & 44.5336 & 0.0011 \\
Residual & 1.261 & 5 & 0.2522 & & \\
Lack of Fit & 1.1421 & 3 & 0.3807 & 6.4057 & 0.138 \\
Pure Error & 0.1189 & 2 & 0.0594 & & \\
Cor Total & 173.7035 & 14 & & & \\
\hline
\end{tabular}

Note. $\mathrm{R}^{2}=0.9927$, Adj- $\mathrm{R}^{2}=0.9797, \mathrm{CV}=1.9142 \%$. 
The three-dimensional response surface shown in Figure 1 was based on Equation 3 and displayed the influence of the variable on extraction yield. One variable was kept constant at an intermediate level while the other two were changed within their respective experimental ranges. The other less significant parameters, ultrasonic power and solvent to solid ratio were set at $400 \mathrm{~W}$ and $30: 1 \mathrm{~mL} / \mathrm{g}$, respectively. It was concluded from Figure $1 \mathrm{~A}$ that the extraction yield has a positive linear relationship with ultrasonic time. The extraction yield increased slowly with increased ultrasonic time and an increases in ethanol concentration from $50 \%$ to $55 \%$, and the resulting response surfaces showed a relatively steep curve with sonication time while the changed the ethanol concentration yield a slightly decrease. Prolonged sonication time and a balanced ethanol/water solvent may have enhanced the extraction yield by water's swelling effect on the plant material and an increase of contact surface area between the plant matrix and solvent. resulting in increased of the extraction yield (Huang et al., 2009).The interactive effects of the extraction times and ethanol concentration on extraction yield were shown in Figure 1B, the extraction yield mainly depended upon extraction times. When the ethanol concentration was kept at the lower level, the extraction yield increased with the increase of extraction times. Furthermore an increase of the ethanol concentration more than $55 \%$ caused a slight decrease in extraction yield. Therefore, the interactive effect of ethanol concentration and extraction times on extraction yield was significant, and could be derived from the Table 3, as the "Prob $>$ F" $<0.001$ was significant. It was observed in Figure 1C that when other parameters were kept constant, varying the extraction times from 1 to 3 , and the ultrasonic time from 50 to 70 min, the extraction yield increased with increasing ultrasonic time and extraction times. Maximum flavonoids extraction yield were observed at a higher ultrasonic time and ultrasonic times.
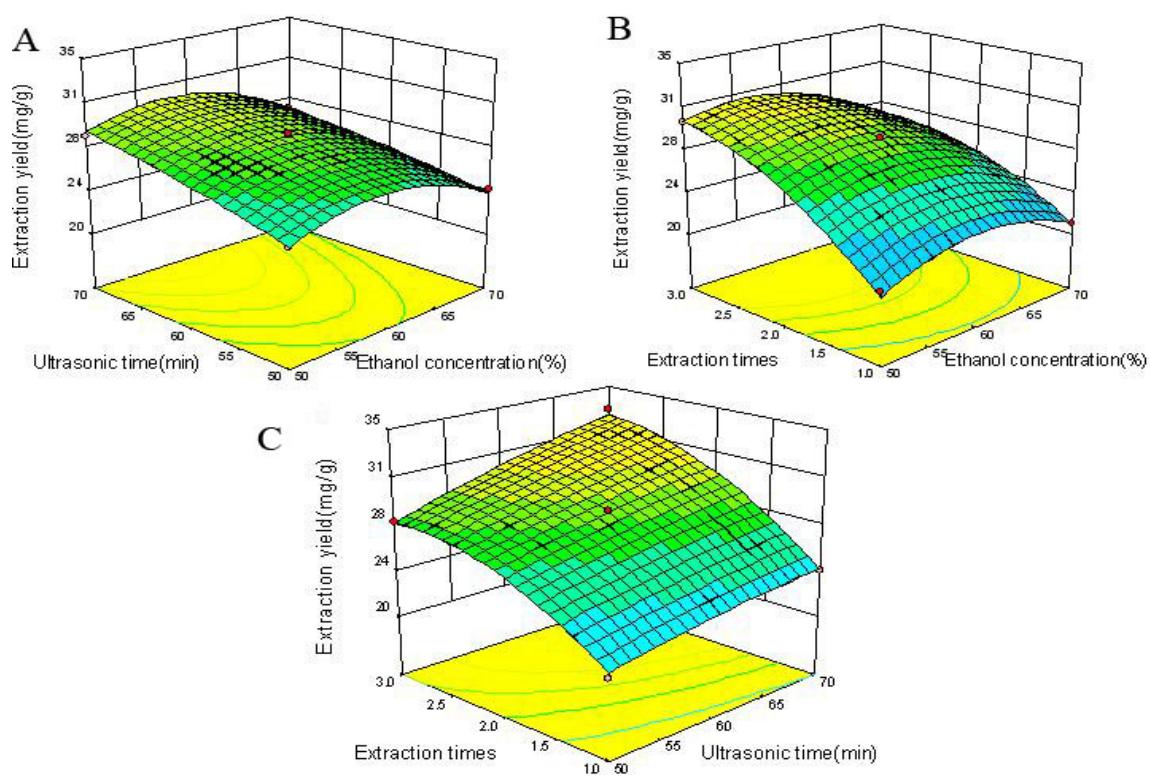

Figure 1. Response surface plots of Cryptotaenia japonica Hassk (A) showing the effect of ultrasonic time and ethanol concentration, (B) showing the effect of extraction times and ethanol concentration, (C) showing the effect of extraction times and ultrasonic time on total flavonoids extraction yield

\subsection{Validation of the Models}

An optimization study was performed to validate the adequacy of the models equation. The optimal extraction conditions determined by the models were as follows: ethanol concentration of $55.13 \%$, an extraction time of 70 $\mathrm{min}$ and three cycles, and the maximum results were $33.093 \mathrm{mg} / \mathrm{g}$. To ensure the operation convenience, experiment was performed using the modified optimal conditions: $55 \%$ ethanol concentration, ultrasonic time of $70 \mathrm{~min}$, three cycles, respectively. The Experimental value was $33.112 \pm 0.742 \mathrm{mg} / \mathrm{g}$ which was in agreement with the predicted value $(33.093 \mathrm{mg} / \mathrm{g})$ and validated the model.

\subsection{Antioxidant Activity and Antioxidant Compositions Analysis}

The extracts under the optimum condition were combined together to reduce ethanol under the vacuum and were further lyophilized with lyophilizer to obtain the crude flavonoids $(0.101 \pm 0.031 \mathrm{~g} / \mathrm{g}$ dry weight powder). The antioxidant capacities of crude flavonoids were shown in Figure 2. When the concentration of crude flavonoids 
increased from 0.1 to $3.0 \mathrm{mg} / \mathrm{mL}$, the DPPH radical scavenging activity increased from $23.18 \pm 0.1 \%$ to $79.87 \pm$ $2.7 \%$, the values of hydroxyl scavenging effects ranged from 0 to $71.60 \pm 2.6 \%$, and the reducing power from $0.035 \pm 0.013$ to $1.200 \pm 0.053$. With regards to EC50, the EC50 values for DPPH radical, hydroxyl radical scavenging activity and reducing power were found to be $0.861 \pm 0.068 \mathrm{mg} / \mathrm{mL}, 1.259 \pm 0.106$ and $1.818 \pm$ $0.560 \mathrm{mg} / \mathrm{mL}$, respectively. The results indicated that the crude flavonoids from $C$. japonica have relative high antioxidant activities and the effects increased with increasing the concentration of flavonoids. At a relatively high concentration $(3.0 \mathrm{mg} / \mathrm{mL})$ of flavonoids, much higher antioxidant activity was not generated which could have resulted from a lower purity of crude flavonoid. The major flavonoid compositions were identified and quantified by HPLC and was showed in Figure 3B. Only several constituent peaks were found in the extract, where the main components of the flavonoids were identified as luteolin and apigenin which were consist with $\mathrm{Li}$ and $\mathrm{Niu}$ (2010). Upon quantification of luteolin and apigenin, the results indicated $15.18 \mathrm{mg} / \mathrm{g}$ and $0.985 \mathrm{mg} / \mathrm{g}$, respectively. A strong correlation between luteolin and apigenin with above antioxidant activities indicated that luteolin and apigenin were major contributors of antioxidant activity of $C$. japonica. As these two antioxidants have been demonstrated to have high antioxidant capacity by various research investigations (Gao et al., 2012; Zhang, Gan, Shelar, Ng, \& Chew, 2013; Žugić et al., 2014).

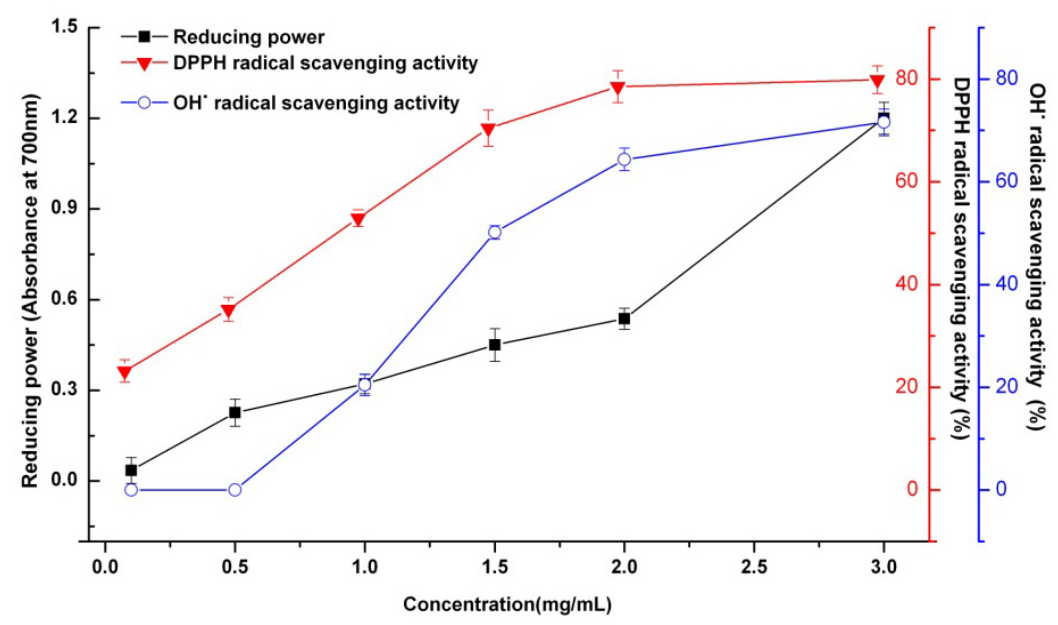

Figure 2. Antioxidant activity of different flavonoids concentration (A). ( $\boldsymbol{a})$ reducing power, ( $\nabla$ ) DPPH radical scavenging activity and $(\mathrm{O}) \mathrm{OH} \bullet$ radical scavenging activity (mean $\pm \mathrm{SD}, \mathrm{n}=3$ )
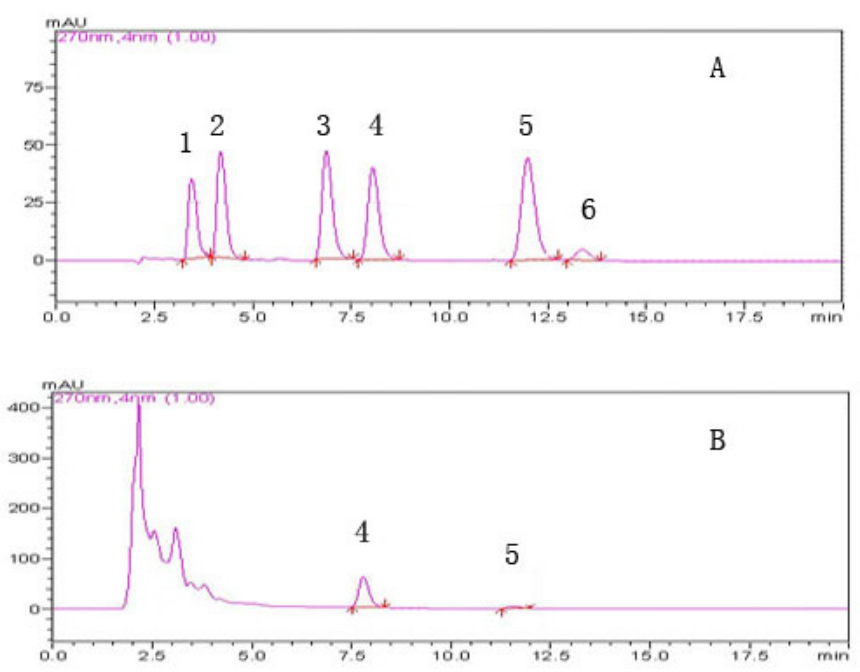

Figure 3. HPLC chromatogram of (A) standard reference and (B) crude flavonoids extracted by UAE (1, hyperin; 2, quercetin-3-rhamnoside; 3, quercetin; 4, luteolin; 5, apigenin; 6, isorhamnetin) 


\section{Conclusions}

In this study, the optimum conditions of ultrasound-assisted extraction (UAE) and antioxidant activity of flavonoids from Cryptotaenia japonica Hassk. were investigated. The optimal conditions of UAE were achieved based on response surface methodology with Box-Behnken design. Under these optimal extraction conditions (ultrasound power: $400 \mathrm{~W}$, ethanol concentration: $55 \%$, extraction time: $70 \mathrm{~min}$, solvent to solid ratio: $30 \mathrm{~mL} / \mathrm{g}$, and 3 cycles extraction). The highest extraction yield of flavonoids was $33.112 \pm 0.742 \mathrm{mg} / \mathrm{g}$, which was well consistent with the predicted value $(33.093 \mathrm{mg} / \mathrm{g})$. It revealed that the ultrasonic-assistance extraction is an effective method for $C$. japonica flavonoids extraction. The antioxidant activities evaluation and HPLC analysis showed that the extracts had moderate antioxidant capacities and luteolin and apigenin were the major flavonoid component in the extracts. Our results provide basic of scientific evidence to further the exploitation and application of the resource. The present study also indicated that $C$. japonica can be considered as good sources of antioxidant flavonoid compounds.

\section{Acknowledgements}

The authors gratefully acknowledge the financial support of this study by Grain-oil Process and Quality Control 2011 Collaborative and Innovative Grant from Hunan Province (Xiangjiaotong (2013) 448), the Scientific Research Project of the Education Department of Hunan Province (13C1158), the National Science-technology Support Plan Projects (2012BAC01B07, 2012BAD29B05).

\section{References}

Bimakr, M., Rahman, R. A., Taip, F. S., Ganjloo, A., Salleh, L. M., Selamat, J., \& Zaidul, I. S. M. (2011). Comparison of different extraction methods for the extraction of major bioactive flavonoid compounds from spearmint (Mentha spicata L.) leaves. Food Bioproducts Processing, 89, 67-72. http://dx.doi.org/10.1016/j.fbp.2010.03.002

Cheng, M. C., Lin, L. Y., Yen, Y. H., \& Yu, T. H. (2010). Chemical Composition and antioxidant activity of the essential oils from the stems and leaves of mountain celery (Cryptotaenia japonica Hassk). Taiwanese Journal of Agricultural Chemistry and Food Science, 48, 33-45.

Cheng, M. C., Lin, L. Y., Yu, T. H., \& Peng, R. Y. (2008). Hypolipidemic and antioxidant activity of mountain celery (Cryptotaenia japonica Hassk) seed essential oils. Journal of Agricultural and Food Chemistry, 56, 3997-4003. http://dx.doi.org/10.1021/jf703593v

Cherng, J. M., Chiang, W., \& Chiang, L. C. (2008). Immunomodulatory activities of common vegetables and spices of Umbelliferae and its related coumarins and flavonoids. Food Chemistry, 106, 944-950. http://dx.doi.org/10.1016/j.foodchem.2007.07.005

Cushnie, T. P., \& Lamb, A. J. (2011). Recent advances in understanding the antibacterial properties of flavonoids. International Journal of Antimicrobial Agents, 38(2), 99-107. http://dx.doi.org/10.1016/j.ijantimicag.2011.0 2.014

Flores, G., Wu, S. B., Negrin, A., \& Kennelly, E. J. (2015). Chemical composition and antioxidant activity of seven cultivars of guava (Psidium guajava) fruits. Food Chemistry, 170, 327-335. http://dx.doi.org/10.1016/j.foodchem.2014.08.076

Gao, Y., Zhao, J., Zu, Y., Fu, Y., Liang, L., Luo, M., ... Efferth, T. (2012). Antioxidant properties, effects on superoxide dismutase and glutathione reductase activities in HepG2 cells with a fungal endophyte producing apigenin from pigeon Pea [Cajanus cajan (L.) Millsp.]. Food Research International, 49, 147-152. http://dx.doi.org/10.1016/j.foodres.2012.08.001

Grigonis, D., Venskutonis, P. R., Sivik, B., Sandahl, M., \& Eskilsson, C. S. (2005). Comparison of different extraction techniques for isolation of antioxidants from sweet grass (Hierochloë odorata). The Journal of Supercritical Fluids, 33, 223-233. http://dx.doi.org/ 10.1016/j.supflu.2004.08.006

Guo, T., Wei, L., Sun, J., Hou, C. L., \& Fan, L. (2011). Antioxidant activities of extract and fractions from Tuber indicum Cooke \& Massee. Food Chemistry, 127, 1634-1640. http://dx.doi.org/10.1016/j.foodchem.2011.02. 030

Huang, W., Xue, A., Niu, H., Jia, Z., \& Wang, J. (2009). Optimised ultrasonic-assisted extraction of flavonoids from Folium eucommiae and evaluation of antioxidant activity in multi-test systems in vitro. Food Chemistry, 114, 1147-1154. http://dx.doi.org/ 10.1016/j.foodchem.2008.10.079

Joana Gil-Chávez, G., Villa, J. A., Fernando Ayala-Zavala, J., Basilio Heredia, J., Sepulveda, D., Yahia, E. M., \& 
González-Aguilar, G. A. (2013). Technologies for Extraction and Production of Bioactive Compounds to be Used as Nutraceuticals and Food Ingredients: An Overview. Comprehensive Reviews in Food Science and Food Safety, 12(1), 5-23. http://dx.doi.org/10.1111/1541-4337.12005

Kang, S. Y., Kang, J. Y., \& Oh, M. J. (2012). Antiviral activities of flavonoids isolated from the bark of Rhus verniciflua stokes against fish pathogenic viruses In Vitro. The Journal of Microbiology, 50, 293-300. http://dx.doi.org/10.1007/s12275-012-2068-7

Kiani, H., Sun, D. W., Zhang, Z., Al-Rubeai, M., \& Naciri, M. (2013). Ultrasound-assisted freezing of Lactobacillus plantarum subsp. Plantarum: The freezing process and cell viability. Innovative Food Science \& Emerging Technologies, 18, 138-144. http://dx.doi.org/10.1016/j.ifset.2012.12.012

Li, C. S., Zhu, D., \& Deng, J. (2006). Study on the extraction technology and determination of flavonoids in Crytotaenia japonica. Food Science, 27, 357-360.

Li, S. H, \& Niu, Y. Y. (2012). Study on chemical constituents in Cryptotaenia japonica. Chinese Traditional Herbal Drug, 43, 2365-2368.

Okude, T., \& Hayashi, S. (1970). Sesquiterpene constituents of the essential oil of mitsuba (Cryptotaenia japonica Hassk). Bulletin of The Chemical Society of Japan, 43, 2984-2985. http://dx.doi.org/10.1246/bcsj.43.2984.

Pourcel, L., Routaboul, J. M., Cheynier, V., Lepiniec, L., \& Debeaujon, I. (2007). Flavonoid oxidation in plants: from biochemical properties to physiological functions. Trends in Plant Science, 12, 29-36. http://dx.doi.org/10.1016/j.tplants.2006.11.006

Şahin, S., \& Şamlı, R. (2013). Optimization of olive leaf extract obtained by ultrasound-assisted extraction with response surface methodology. Ultrasonics Sonochemistry, $20, \quad 595-602$. http://dx.doi.org/10.1016/j.ultsonch.2012.07.029

Wang, X., Wu, Y., Chen, G., Yue, W., Liang, Q., \& Wu, Q. (2013). Optimisation of ultrasound assisted extraction of phenolic compounds from Sparganii rhizome with response surface methodology. Ultrasonics Sonochemistry, 20, 846-854. http://dx.doi.org/10.1016/j.ultsonch. 2012.11.007

Yang, W. P., Xia, T. H., Li, C. D., \& Cheng, Q. H. (2010). New Chinese herbal medicine map and the commonly used formula 4. Guiyang: Guizhou science and technology press. http://dx.doi.org/10.1016/B978-0-7020-3132-8.00010-4

Yao, Y., \& Ren, G. (2011). Effect of thermal treatment on phenolic composition and antioxidant activities of two celery cultivars. LWT-Food Science and Technology, 44, 181-185. http://dx.doi.org/10.1016/j.lwt.2010.07.001

Yao, Y., Sang, W., Zhou, M., \& Ren, G. (2010). Phenolic composition and antioxidant activities of 11 celery cultivars. J Journal of Food Science, 75, C9-C13. http://dx.doi.org/10.1111/j.1750-3841.2009.01392.x

Zhang, G., He, L., \& Hu, M. (2011). Optimized ultrasonic-assisted extraction of flavonoids from Prunella vulgaris L. and evaluation of antioxidant activities in vitro. Innovative Food Science \& Emerging Technologies, 12, 18-25. http://dx.doi.org/10.1016/j.ifset.2010.12.003

Zhang, Y. C., Gan, F. F., Shelar, S. B., Ng, K. Y., \& Chew, E. H. (2013). Antioxidant and Nrf2 inducing activities of luteolin, a flavonoid constituent in Ixeris sonchifolia Hance, provide neuroprotective effects against ischemia-induced cellular injury. Food and Chemical Toxicology, 59, 272-280. http://dx.doi.org/10.1016/j.fct.2013.05.058

Zhu, H., Wang, Y., Liu, Y., Xia, Y., \& Tang, T. (2010). Analysis of flavonoids in Portulaca oleracea L. by UV-vis spectrophotometry with comparative study on different extraction technologies. Food Analytical Methods, 3, 90-97. http://dx.doi.org/10.1007/s12161-009-9091-2

Zielinski, A. A. F., Haminiuk, C. W. I., Alberti, A., Nogueira, A., Demiate, I. M., \& Granato, D. (2014). A comparative study of the phenolic compounds and the in vitro antioxidant activity of different Brazilian teas using multivariate statistical techniques. Food Research International, 60, $246-254$. http://dx.doi.org/10.1016/j.foodres.2013.09.010

Žugić, A., Đorđević, S., Arsić, I., Marković, G., Živković, J., Jovanović, S., \& Tadić, V. (2014). Antioxidant activity and phenolic compounds in 10 selected herbs from Vrujci Spa, Serbia. Industrial Crops and Products, 52, 519-527. http://dx.doi.org/10.1016/j.indcrop.2013.11.027 


\section{Copyrights}

Copyright for this article is retained by the author(s), with first publication rights granted to the journal.

This is an open-access article distributed under the terms and conditions of the Creative Commons Attribution license (http://creativecommons.org/licenses/by/3.0/). 